\title{
Cooperative Learning by Teacher Trainers as a Tool for Improving Teacher Training in Heterogeneous Elementary School Track Classes
}

\author{
Smadar Galili \\ Elementary school Teachers Training department, The David Yellin Academic College of Education, Jerusalem, Israel \\ *Corresponding author: galili-s@bezeqint.net
}

Received June 16, 2014; Revised July 07, 2014; Accepted July 18, 2014

\begin{abstract}
This article presents research conducted in the Elementary School Department at the David Yellin Academic College of Education. The purpose of the present study is to use the action research approach to examine and illuminate the processes of professional development that occurred among a group of teacher trainers (teaching practice supervisor) over a series of cooperative learning sessions. The purpose of the learning sessions was to reinforce and expand the trainers' training and teaching styles by introducing clear standards and ensuring the careful and spiral learning of tools, skills, and practical strategies suited for teaching work in the heterogeneous class. The goal of this process was to enhance the students' ability to cope with the task of teaching in a heterogeneous class during their first few years in the field, and indeed throughout the course of their career. The findings of the research are presented according to the three periods during which the teacher trainers' learning sessions were conducted with the three participating groups: veteran teacher trainers, new teacher trainers and students. The findings reflect the influence of the cooperative learning processes on the training style of the teacher trainers, on the content taught by new and veteran teacher trainers and on the students' teaching practice.
\end{abstract}

Keywords: teacher trainers (teaching practice supervisor), students, adapted strategies, heterogeneous class, training style.

Cite This Article: Smadar Galili, “Cooperative Learning by Teacher Trainers as a Tool for Improving Teacher Training in Heterogeneous Elementary School Track Classes.” American Journal of Educational Research, vol. 2, no. 8 (2014): 568-576. doi: 10.12691/education-2-8-2.

\section{Preface}

Many new teachers complete their studies successfully but face frustration and significant challenges during the first years of their work as teachers (Orland-Barak, 2002). The new teachers describe a gap between their experiences on entering the educational field and the training process. This gap relates to skills, capabilities, and strategies for responding to the needs presented by pupils in heterogeneous classes.

The research literature includes extensive discussion of diverse support programs implemented during the intake of new teachers and during their first few years working in schools (Zilberstein, 2013). However, very little attention is paid to the training programs for students and the extent to which these programs properly prepare the graduates and contribute to their intake in the education system. I believe that this gap obliges those of us involved in training teachers to engage in a thorough re-examination of the training process for which we are responsible. We must consider ways to change this process in order to minimize the gap felt by new teachers as they begin their work in the field.
Accordingly, the training process for elementary school teachers should take into account the differences between individual pupils in heterogeneous classes, including appropriate strategies for coping with these pupils' needs. This will ensure that the teachers are better prepared to perform their required role in the educational field (Koster \& Dengerink, 2008; Cochran-Smith \& Power, 2010) and will reduce the gap discussed above.

\subsection{Styles of Pedagogic Training}

Three key approaches can be identified in training work in teacher training institutions (Kenan \& Assaf, 2004).

The first approach, known as the consultative approach, places the teaching student at the center of the process. The instructor's principal function is to provide the students with emotional support in order to help them cope with the shock of reality in the educational field and to moderate emotional pressures. The training style of these teacher trainers is usually described as responsive, consultative, and supportive (Tomer, 2000), or as personal and emotional (Buber,1963; Zilberstein \& Katz, 1994; Schuck et al., 2008). Trainers with a dominant consultative training style have a generalized training plan that is based mainly on needs raised by the students 
themselves and is not rooted in any defined standards (Cochran-Smith \& Power, 2010).

The second approach is known as the teaching approach. According to its principles, learning should emphasize practical knowledge and knowledge about the social culture of the school in which teaching occurs. The teaching style of these trainers is usually described as teaching-oriented with a formative professional approach (Zilberstein, 2002; Tomer, 2000; Kenan \& Assaf, 2004), or as a cognitive-professional style (Schuck et al., 2008).

This training has a "clinical" and detailed quality and is supported by clear and practical standards required in everyday reality in the educational field (Koster \& Dengerink, 2008; Cochran-Smith \& Power, 2010). Clear standards can help students implement processes of selfevaluation and peer evaluation, alongside the evaluation provided by the teacher trainers and on the basis of the same criteria thereby significantly advancing the students' processes of professional development (Van Diggelen, Den Broke \& Beijard, 2013).

Teacher trainers who favor the teaching approach serve as a role model for their students. In each lesson they present pedagogic theories in a practical and applied manner, enabling the students to experience different learning styles and creating a bridge of understanding between theory and practice (Lundberg et al., 2007; Thygguason, 2009).

The third approach, known as the combined approach, blends elements of both methods described above, resulting in a combined consultative and teaching approach. This is reflected by supporting the individual's emotional needs and capabilities as a platform for professional development combined with the expansion of the student's professional knowledge and its application in teaching (Tomer, 2000).

Various studies have found that approximately twothirds of teacher trainers consider behaviors that help students and develop their reflective capabilities (a consultative training approach) as more important, while only one-third attached greater importance to inculcating knowledge, connecting it to the act of teaching, and providing basic teaching skills (Bar Ziv, 2002).

\subsection{Training Methods for Teaching in the Heterogeneous Class}

Teaching methods in a heterogeneous class, including practical tools and strategies for different pupils, were the theoretical and practical basis for the learning sessions held for the group of teacher trainers in the elementary school track.

A heterogeneous class is one in which the level of diversity between the different pupils is large enough to create substantial gaps in their functioning. The causes of this diversity are personality-related, psychological, sociocultural, and sociological (Chen, 1989; Ben Ari \& Rich, 1994).

In keeping with the principle of social justice, the teacher must recognize diversity among the pupils and ensure that each pupil attains the required academic achievements. To this end, the teacher must gain a command of a broad range of teaching and learning strategies which can then be adapted to meet the differing needs of individual pupils (Beck, 2013).
Strategies and tools adapted to the needs of different pupils in the heterogeneous class enable teaching staff to find ways to cope with diversity among their pupils, to listen attentively to their voices, and to learn to thoroughly observe them as they attempt to realize their academic, social, and personality-related goals (Avissar, 2009). This will enable each pupil- from those who face the greatest challenges to the most outstanding pupil - to find their place within a heterogeneous class that provides possibilities for learning and for individual and social development for a wide range of learners (Crono \& Snow; Brickner, Zahavi \& Hacham, 1997).

\subsection{The Research Question}

How do joint learning processes for a group of teacher trainers, including practical tools and strategies relating to teaching in the heterogeneous class, influence the training style of the teacher trainers, the content learned in the didactic classes, and the students' teaching practice in schools?

\section{Methodology}

\subsection{Action Research}

Action research is the study of a given situation in order to improve the quality of the action in that situation. Action research is conducted by a researcher who is herself an active partner in the study; by means of reflective processes carried out by the participating researcher; it enables assessment and amendment of the process being examined (Elliot, 1991). Cohen et al. (2000) add that action research is a combination of research and action, in which a person tries to understand and to improve a certain practice. It is a minor intervention in the functioning of a real world and an examination of the effects of this intervention.

Therefore I choose to research the study of practical tools and adapted strategies for teaching in the heterogeneous class in cooperative learning sessions by the group of teacher trainers through action research methodology. The open and declared goal of this approach is to ensure that these themes constitute a central axis in the trainers' training programs in the context of this action research. This axis is perceived as an important component in expanding and consolidating the teaching training style (Keinan \& Assaf, 2004), supported by clear standards and the consultative style (Shuck et al, 2008) common among some of the experienced trainers in the elementary school track.

As the researcher in this action research, I made no claim to corroborate or refute any particular hypotheses. Rather, my goal was to study and develop joint approaches with the teacher trainers and students while acquiring data through a dynamic process of a "spiral continuum” (Ayalon \& Tzabar Ben Yehoshua, 2009). This process does not constitute a fixed and predetermined action plan (Hacohen \& Zimran, 1999), but rather a methodological structure that developed in keeping with the unique conditions dictated by the research field. While implementing the learning sessions for the teacher trainers, I examined the possibility of introducing changes through conversations and interviews with teacher trainers and 
students, and accordingly I amended and improved aspects of the process plan.

\subsection{The Action Research Stages}

Evaluating the current situation and identifying the subject as the start of the research process: After I assumed the role of head of the elementary school track, I began to implement this stage. I examined the subject via meetings and discussions with teacher trainers and students.

On the basis of the information collected, the problem was defined as the absence of a teaching style, leading to a lack of applied tools and practical strategies suited to teaching in a heterogeneous class.

Initial planning and preparations: Planning a series of joint learning sessions with the group of teacher trainers in the elementary school track to examine principles, tools, and strategies for adapted teaching in the heterogeneous class.

Implementation of the plan: Implementation began in 2011 with planning, followed by joint learning meetings with the group of teacher trainers in the elementary school track. This included study of practical tools and applied strategies for teaching in the heterogeneous class with the goal of implementing these approaches in training and in the evaluation of students.

Evaluation of the action: The evaluation process was developed and implemented throughout the course of the study by means of focused questions monitoring the implementation of the action plan and the examination of interim findings in order to ascertain whether the study was developing in accordance with the predetermined goals (Hacohen \& Zimran, 1999). During the study I held discussions on the interim findings with the teacher trainers and the students. On the basis of the findings and at the teacher trainers' request, two unscheduled sessions were arranged for joint reflective discourse by the trainers relating to the themes studied and possibilities for their implementation in the training processes.

During the learning sessions, teacher trainers committed to self-criticism and reflection, engaged in learning and change relating to their everyday work (Wallace, 2002).

Despite the discrepancies that emerge during action research and planning for the implementation of change in the educational field, such research can ensure meaningful change (Patthey \& Thomas-Spiegel, 2013). Accordingly, I identified this methodology as the most suitable for the study.

\subsection{The Participants in the Study}

Teacher Trainers- nine veteran trainers (20 years or more as Teacher trainers) and six new trainers (2-5 years as Teacher trainers) .

\subsection{Students}

The study included 130 students in the elementary school track. Over the course of the year data were collected systematically through observation of lessons taken by 30 of the students and discussions with all the student groups during my visits to schools. Discussions also took place during meetings of the student forum in the elementary school track, with whom I met on a regular basis.

Four students (two in second year and two in third year) were selected for in-depth interviews.

\subsection{The Researcher}

My simultaneous function as head and researcher in the elementary school track meant that I was a key participant in the developments in the research field both as a researcher and as the head of elementary school track leading the process of change. During the study I attempted to avoid critical and/or patronizing attitudes (Hayman, 2006) relating to the complex and difficult work of the teacher trainers. I also attempted to avoid "sitting on the fence" as a critical observer. Instead, my objective was to take responsibility for implementing change by leading and guiding the joint learning processes of the teacher trainers; to be attentive and empathetic; and to provide space to include the unique personality and needs of each of them. As a researcher engaged in the process of change, I attempted to be as sensitive as possible during the different observations and in interpreting events and processes in which I am involved. My own significant involvement in the process also required me to expose weaknesses. As far as possible I attempted to raise difficulties and obstacles without personal bias, and to seek ways to honestly solve problems with a sense of moral responsibility (Hayman, 2006).

\subsection{Research Tools and Data Collection Process}

\subsubsection{Conversational Events}

By means of conversations (Mishler, 1986) I conducted and documented with all the teacher trainers and with all the student groups in the elementary school track over the course of the year (during my visits to schools; feedback conversations in the middle and at the end of the year; and documentation of the joint learning sessions), I learned how they perceived their role and the principles, tools, and themes they teach the students.

\subsubsection{In-Depth Interviews}

I held two in-depth, semi structured interviews with four students: one at the beginning of the research process and another at the end of the process. Similarly, I held two in-depth, semi structured interviews, with four teacher trainers - two veteran trainers and two new trainers, one at the beginning of the research process and another at the end.

\subsubsection{Observations}

External observations: I undertook external observations of 30 students from different training groups in the training classes they took as part of their teaching practice over the course of the year. My observations of students over the course of the study provided an opportunity to examine which principles and tools acquired in the training sessions with the teacher trainers were being implemented by the students in class.

I took into account possible distortions during the observations due to the possibility that my combined role 
as a researcher and as head of the elementary school track may distract the students and disturb the natural conditions in which the lesson would usually take place.

\subsubsection{Participatory observations}

I maintained a detailed record of each learning session (10 sessions over the year) for the teacher trainers, including a record of nonverbal evidence.

The records and participatory observations offered me a chance to study the learning process that takes place during the sessions on the basis of the opinions, thoughts, and insights expressed by the teacher trainers. This in turn helped me decide on changes or on the need to return to the goals of one session in the next session in order to improve the program and provide solutions for various problems that were relevant to the teacher trainers and to me (Hacohen \& Zimran, 1999).

\subsubsection{Written Feedback}

At the middle and end of the process all the teacher trainers completed written questionnaires including openended questions about the joint learning sessions. This feedback provided a rich source of data testifying to the quality of the trainers' learning processes.

\subsubsection{Reflective Diary}

Throughout the research period I kept a reflective diary in which I documented my thoughts, hesitations, and insights.

\subsubsection{Data Processing}

In order to create a productive description of the sources and testimonies and validate the study, I undertook triangulation of the different sources collected during the research year. The triangulation offered an opportunity to examine the events from different perspectives in order to yield a more accurate and reliable description (Hacohen \& Zimran, 1999). Through repeated readings of the data I attempted to identify recurring themes and issues in the primary findings (Ayalon \& Tzabar Ben Yehoshua, 2009) relating to my research question as the main focus of attention. I arranged the different themes in key categories (core categories).

\section{The Findings}

The findings are presented for the three groups that participated in the study - *veteran teacher trainers

* New teacher trainers

*The student group

According to the three periods in which the study was implemented:

1. Evaluating the situation and locating the theme as a starting point of the research process

2. During the implementation of the joint learning sessions.

3. At the end of the year - on completion of the learning sessions.

\subsection{Evaluating the Situation and Locating the Theme as the Starting Point of the Research Process in the Teacher Trainers Group}

For this stage, which was implemented prior to the joint learning sessions of the teacher trainers in the elementary school track, I aimed to consolidate the group of trainers, coordinate expectations, and collect data serving as the basis for formulating the goals and content of the learning sessions. This process enabled the advancement of a positive work climate (Lyman \& Foyle, 1993).

During this stage, principled differences of approach emerged regarding the essence and goals of the teacher trainer sessions and the contents of pedagogic training between the veteran teacher trainers and the newcomers to the elementary school track.

\subsubsection{The Veteran Teacher Trainers:}

\section{A “Nature Reserve" Where All Sit Together}

Joint work in most of the teacher trainer groups shared a common feature: they are based on interpersonal relations, and the emphasis on these relations exerts a strong influence on the work process. This situation can be termed a "nature reserve" (Keinan \& Assaf, 2004) in which the members of the group work autonomously in a closed group created by the staff. The group of veteran teacher trainers in the elementary school track has worked together for years as a support and sharing unit. Most of the sessions focused on raising and discussing dilemmas from the field. During the formulation of the goals and content of the joint learning sessions, most of the veteran teacher trainers expected the same sense of togetherness and belonging that have always been part of their sessions:

"For me, the most important thing is to meet together. It doesn't make any difference what we do together - even meditation. The main thing is to be together..." (Veteran teacher trainer).

Another teacher trainer recalled the special atmosphere and feelings that accompanied past meetings of the trainers in the track:

"Years ago... we would sit down, share things we had learned with each other, discuss different pupils, and so on... it was so good, so reinforcing ..."

Some of the veteran teacher trainers expressed opposition to the idea of creating a clear and uniform standard for evaluating the student's teaching unit:

"Something that really bothers us about the feedback and what it includes... it is wrong to teach using a clear format and standards. I think the challenge must be authentic, relevant, and spontaneous and then you can choose..."

Another veteran teacher trainer claims that clear standards for evaluating a lesson obscure the overall picture:

“... when you magnify the details, you lose the overall picture. You need to take an overall view. I believe that we need to look at processes, not at details."

From an email I received from a veteran teacher trainer:

“...I am not sure whether the answer lies in clear standards for evaluating students, or rather in a very profound education, almost like Plato's description in his Allegory of the Cave when he speaks of directing the eyes of the soul..." (January 2011).

It emerges from the conversations that the consultative training style (Zilberstein \& Katz, 1994) typifies the training work of most of the veteran teacher trainers in the elementary school track. 


\subsubsection{New Teacher Trainers}

\section{elements of the teaching approach}

While most of the veteran teacher trainers in the elementary school track clearly adhered to the consultative training style before the commencement of the joint learning process, it was possible to identify among the new teacher trainers in the elementary school track elements of the teaching approach, which assumes that training must take place within the school context and be based on case study (Zilberstein, 2002).

From an interview with a new teacher trainer:

"I am very careful to make sure that by the end of the year everyone understands... they have come a long way in terms of preparing a lesson plan since the start of the year. This gives them a lot of confidence, and when they are standing in front of a class and they have confidence and a framework they can also show flexibility... I'm a very planned and orderly person..."

A new teacher trainer explains her need to present the students with clear demands:

“...because they don't have knowledge and they need to know clearly what is expected of them. The demands must be structured; there must be clear tools... This helps them a lot. They need to know how to swim. Planning also gives me the confidence to make changes... I tend to be more teaching-oriented and focused...”

\subsubsection{The Student Group}

A Lack of Practical Tools and Adapted Strategies for Teaching in the Heterogeneous Class.

During the external observations of the students trained by the veteran teacher trainers, I notice the lack of practical tools and adapted strategies for teaching in the heterogeneous class.

From an observation of a second-year student:

"The goals of the lesson are unclear... The pupils mainly seem to be having an experience and enjoying themselves... What new learning is supposed to be taking place? Everyone gets the same task - there is no recognition of differences..."

My in-depth interviews with students who completed the first and second years raised the issue of the lack of practical teaching tools, focused and clear guidance, and the definition of clear standards for evaluating the training processes they had undergone:

"It was only at the end of the year that I realized that the function of the teacher trainer is to teach me, and not only to evaluate a lesson plan, when in most cases the feedback is 'very nice.'... It bothered me that they didn't require us to plan and run a lesson on a high standard. All the time I felt a kind of accepting approach - 'whatever you do will be fine.' When they make demands of you and you know what the demands are, that can really help...”

"We lacked teaching tools, the basic foundation stones of a teacher... They should present the students with the goals of didactic training and then we could compare the hierarchical progress. There is no clear progress and hierarchy from the beginning of the first year through to this point...”

\subsection{During the Implementation of the Learning Sessions}

\section{In the Teacher Trainers Group}

As in the previous stage, a significant difference continued to be seen between the veteran teacher trainers and the newcomers in the implementation stage.

\subsubsection{Veteran Teacher Trainers}

\section{Learning without implementation.}

The veteran teacher trainers testify that they learned themes from the various sessions, but it is not possible to identify the implementation of this in their training work with the students.

"I'm at a point where I don't know what to do with what $I$ received in the learning session relating to teaching in a heterogeneous class. I also have themes I want to transmit and at this stage what I learned doesn't form part of this...” (A veteran teacher trainer).

In an interview with another veteran teacher trainer, I hear opposition to implementing what has been learned in the sessions:

“I really don't need or want anything anymore... Through December I just let the students work almost without guidance... I respond to requests and answer their questions... I'm always available... They are my curriculum and I am their curriculum."

In my observation of the work of students trained by veteran teacher trainers during their practice in schools, I cannot identify the implementation of what was learned in the sessions. The teaching is frontal and there is no adaptation of the study materials or group work. I did not see the teacher trainers providing the students with feedback after observing their work in the classroom:

"I observed three students. The classes were very frontal and standard. I could not see any evidence in the students' teaching that they had acquired practical tools for managing the lesson or for working in a heterogeneous class - issues that have already been studied in the learning sessions for the teacher trainers.” (Reflective Diary)

\subsubsection{New Teacher Trainers}

Implement what has been learned.

Most of the new teacher trainers tend to implement what has been learned, not only in their didactic lessons but also in their work accompanying students during their teaching practice.

"Over the course of the week they all send me lesson plans. In some cases I respond on the basis of what we learned in the sessions for the teacher trainers. I relate to the overall plan, and in some cases I completely dissect it. As I see it, our job is to provide feedback so they can change the lesson plan, and to provide at least an hour's feedback after each class I observe. It's important to me to make sure they understood what I told them..." (New teacher trainer).

In a conversation with another new teacher trainer, she reports on the implementation of what she learned in the joint sessions:

"I draw themes directly from the learning sessions for the teacher trainers for my didactic work, such as how to respond to diversity in the class. I synthesize all the themes I teach. Some of the students are already beginning to implement what they learn in the field, and it is particularly important that they absorb these themes..." 
The new teacher trainer's implementation of what has been learned was also evident during my observation in the school where she is working:

“... Each student has a clear indicator based on criteria for evaluating the teaching unit formulated during the training meetings...”

\subsubsection{The Joy of Learning}

During the joint learning sessions, a joy of learning developed among all the teacher trainers who participated, veterans and newcomers alike. The sessions were characterized by openness, cooperation, trust, and mutual support (Bolam et al., 2005), which developed and deepened over the course of the year.

"One of the veteran teacher trainers approached me today and told me: 'It's important for me to look you straight in the eye and tell you that I am really enjoying these sessions and learning so much from them. This process is so right and professional and it's enabling me to develop and to make a lot of progress." (Reflective diary).

A new teacher trainer writes in an email:

"I really enjoyed it. It helped me a lot and I like the pedagogic approach we learn in the sessions. I enjoyed seeing the team work, I liked the active and meaningful learning style, and I learned new things.”

\subsubsection{A Request to Engage in Reflective Joint} Discourse

In April 2012, after they had participated in over half the joint learning sessions, the majority of the teacher trainers asked if we could take a break from the process and engage in reflective discourse.

This is an essential stage in the process of joint learning, which inspires and invites reflection and dialogue and enables the teacher trainers to engage in processes of consultation including listening to other opinions and sharing their thoughts and ideas with their peers (Hargreaves et al., 1996; Donaldson \& Sanderson, 1996).

A veteran teacher trainer writes in her feedback:

"What's missing and what do I think is important to add: I think what's missing are in-depth consultations, an opportunity for us to discuss the content we are studying and raise our doubts about the didactic lessons. Despite the sessions, it feels as though each of us is still working on their own."

From a conversation with a new teacher trainer:

"In the final analysis the sessions are very short. If there was time, I would be happy to hear from the others how they are implementing the principles we studied in that session. It would be interesting to hear and have a chance to discuss what we learn. I think there is a double opportunity here - to get to know each other and to learn from others' experiences.”

These findings enabled me to monitor the implementation of the joint learning sessions, which constituted the action plan in this action research (Hacohen \& Zimran, 1999) and to make changes to the plan. I decided to take a break from the planned program and run two sessions for an in-depth discussion of the various learning processes. The reflective sessions encouraged the teacher trainers to engage in meaningful conversations among themselves and with me, as head of the elementary school track, relating to problems that emerged in implementing the change in the training processes (Wallace, 2002).

In the collected data, the teacher trainers testify that these sessions encouraged in-depth discourse and mutual listening in the group, gave them a sense of professional self-respect, and provided time to process what they had learned.

From the record of the meetings (May 2012):

"I felt as a learner that I was given space to think about a very dense learning process, and I also felt I was respected as a person engaged in learning." (Veteran teacher trainer).

"I thought it was excellent because the three subjects we examined are interrelated. The participants really listened to each other." (Veteran teacher trainer).

"The need arose to process something... Until now it was like one frontal lesson after another (the way we teach the students not to do), so this was significant. When small groups of teacher trainers discuss things together they can process what they have learned, ask questions, and understand.” (New teacher trainer).

A veteran teacher trainer added that the learning sessions effectively result in the development of a pedagogic "credo" for the elementary school track:

“...This year I had the feeling that we were learning things with the goal of developing a common credo for the track. On the one hand we focus on uniform study of content and the development of a uniform tool, while on the other we enjoy a very open approach something I don't feel I could manage without..." (Veteran teacher trainer).

The impression was that the joint discussions among the teacher trainers enabled each one to contribute their knowledge and experience with the goal of creating mutual learning processes (Fielding, 1999).

\subsubsection{Students (During the Implementation of the} Trainers' Learning Sessions)

Significant differences were apparent between students who were trained by veteran teacher trainers and those receiving training from new trainers.

Students trained by new trainers

"Together with a new teacher trainer I observed a student in the middle of her second year. The lesson was extremely well planned and included a very professional discussion with the children about leadership, group play and work with texts on different levels.” (Reflective diary).

The teacher trainer (giving feedback to the student I observed): “It's clear that you put a lot into planning and diversifying the teaching methods, and you managed to find texts on different levels including difficult words. The lesson was very well constructed..."

In a conversation summarizing a day with the students, I asked how they felt about the transition from the first year to the second year, and whether there had been any change in training, in the points emphasized, and so forth.

A.: "I learned a lot in the first year and it really helped me... This year I am getting more information about how to teach - more down-to-earth content about teaching. I'm learning how to reach the children so they can connect to what they're learning... I am 
learning to draw closer to their world and to address the differences between them."

Students trained by veteran teacher trainers

The above findings reveal initial steps to integrate strategies and practical tools for teaching in a heterogeneous class as studied in the joint learning sessions among students who received training from new trainers in the elementary school track. This process reflects a greater emphasis on the teaching style. By contrast, in-depth interviews with two third-year students trained by veteran teacher trainers showed that these trainers' work continued to be dominated by the consultative approach:

“...I need to have a clear and precise understanding of where I'm heading, what I have to aim for, and what aspects I should let go.”

\subsection{At the End of the Learning Process The Teacher Trainers}

\subsubsection{Veteran Teacher Trainers}

Some of the veteran teacher trainers claimed that they were not using the evaluation tools (a tool that evaluates student lessons in a heterogeneous class developed through the learning sessions), and argued that the consistent use of clear criteria for evaluating the students' teaching units impedes the evaluation process:

"I am not comfortable with the formal use of a tool. You know that I do not like principles that are exposed to the students as part of a nurturing discourse and I do not like indicators. I feel that these narrow my interaction with the students and do not sufficiently promote their growth.” (Veteran teacher trainer).

Another veteran teacher trainer testifies that she is more inclined to rely on her gut feelings and her extensive experience than on clear criteria, which she considers restricted her to structured tools:

"Yes, I did look at it (the table of evaluation criteria) from time to time, to help my own internal process of organization ahead of my meetings with the students and with coaching teachers, while I was considering how to talk to them and about what... The fact that I rely on my extensive experience and am also trapped in the working method I have developed over many years makes me work on the basis of instinct most of the time and to use structured tools only when I can't solve problems in my usual spontaneous way...”

\subsubsection{New Teacher Trainers}

The new teacher trainers report consistent use of the evaluation tool, including clear criteria for evaluating the students as the basis for their training plan (Koster \& Dengerink, 2008).

"I presented the indicator I had developed on the basis of the table and used it to explain what we expect, what is relevant to where they (the students) are now and what will apply later. I used the evaluation tool during my feedback on the classes as I went through the criteria." (New teacher trainer)

"I used the table to help me set objectives, coordinate expectations, and evaluate the students in the various stages of learning... This is how I identified our objectives for the year.” (New teacher trainer)
2.3.3. Students at the End of the Learning Process of the Teacher Trainer Group

At the end of the academic year I held in-depth interviews with students to sum up the year's work. The interviews highlighted the difference between the students trained by veteran and new teacher trainers in terms of the content studied in the training sessions and the training style.

Students trained by new teacher trainers:

From an interview:

“This year, I have learned how to write a lesson plan and think about it. What are the goals, understanding the child - what he thinks and how he learns. Not to see the class as a single unit..."

“At first we would just prepare a lesson plan for the whole class. Now I know how to plan a lesson for diverse children... I learned this year how to focus the lesson goals and translate them into teaching for different students in the heterogeneous class... After I began to prepare my lesson plans in this way, I really felt that I was adapting the materials to different children. This brought the whole thing home to me and inspired me with confidence that this is how we need to teach... I prepared different material and everyone learned... I really enjoyed seeing how all the children were studying...”

Students trained by veteran teacher trainers

The students trained by the veteran teacher trainers still report a lack of clarity regarding the criteria for evaluating their teaching:

"I still feel a lack of clear criteria for evaluating my teaching. I go out into the field and miss this. When things are written down it can help me make sense of it, and then I can decide which aspects to emphasize and which things to let go..."

"We really haven't got to all the aspects relating to planning the teacher's time, adapting the materials for different children, and group work... Maybe because the schools still aren't ready for this...”

From my observation of a student at the end of her third year who is being trained by a veteran trainer:

"Y. is very sure of herself and runs the lesson confidently. She has clearly prepared carefully and studied the material in depth. However, most of the lesson is frontal in style. The division of the teacher's time is not well thought out and there are not different tasks for different children..."

From an external observation of a veteran teacher trainer providing feedback for the student:

“The feedback for $Y$. focuses on her feelings about the lesson, reflective evaluation relating to the process the student has undergone since the previous lesson, and reinforcing the student's handling of one of the children who has behavioral difficulties... I didn't see clear criteria for evaluation that $Y$. can use in preparing her lesson...”

\section{Discussion}

The goal of the study presented in this article was to introduce a process of change through an action research in the content of training provided by teacher trainers in 
the elementary school track and in their training style. This was to be achieved by means of joint learning sessions designed to reduce the gap the students experience between their college training and the knowledge and strategies they need in order to cope successfully with teaching in the heterogeneous class. This change included the introduction of practical tools and strategies for teaching in the heterogeneous class and the combination of the teaching style of training alongside the consultative style that is common among most of the teacher trainers.

The action research enables progress and improvement that take place while advancing through the various circles included in the process of change: planning, implementation, guidance, analysis and reflection (Cohen et al., 2000; Wallace, 2002). At this point, after just one year of the learning process in the teacher trainers' group, the first signs show that the trainers are beginning to implement the content acquired in the joint sessions. This is particularly true among the new teacher trainers in the elementary school track. The action research enables me to ask complex questions: How can the change in the teacher trainers' group be promoted and consolidated? What factors impede this process and what factors can motivate and encourage the desired process of change?

Throughout the learning process in the teacher trainers' group, some of the trainers expressed opposition and dissatisfaction - particularly some of the veteran trainers. It is possible that the opposition among the veteran teacher trainers and their reluctance to implement the content of the learning in their training work can be explained by pressure of work and professional and personal burnout. In addition, these teacher trainers may feel that the process of change constitutes a further erosion in their professional autonomy as I attempt - as head of the elementary school track - to make changes that they find unacceptable under what they see as the guise of professional development (Day, 1999).

A further possibility is that the veteran teacher trainers find it difficult to relinquish their perception regarding the nature of teacher training, which functions for them as a safe and familiar framework in which they have believed for many years. The current process of change may be contrary to other goals in which they believe (Cohen, 2011). Accordingly, abandoning a previously-held paradigm entails complex emotional processes and is therefore likely to require a more protracted process (Parag \& Inbar, 1999).

Another factor that may trigger opposition among the veteran teacher trainers is that they did not fathom from the outset why they needed to change their teaching style. As a result, they may have been unable to connect to the principles of this change and thus avoided implementing the change at this stage of the process (Cordingley et al., 2003).

In coping with opposition to the desired change among the veteran teacher trainers, I believe that as head of the elementary school track, I, must take into account their conceptual approach, feelings, beliefs, and educational attitudes (Donaldson \& Sanderson, 1996). The challenge I now face, therefore, is to ensure that all the teacher trainers, and particularly the veteran trainers, are more meaningfully involved in determining the content of the studies in the learning sessions (Day, 2003) Such involvement will help them feel that they are an important part of the process of change and may avoid the sense of coercion or lack of consideration for their professional approaches and needs (Lorrigan, 2001).

Conversely, several factors were found to contribute to the success of the process of change in the teacher trainers' group. The joint learning sessions enabled me and the teacher trainers to develop a common sense of responsibility for the students' professional development and for our own professional development as teacher trainers, and in my case, as the head of the elementary school track (Day, 1999). In addition, the learning sessions expanded and deepened the common professional language shared by all the partners in the study - the students, the teacher trainers, and myself (Hacohen \& Zimran, 1999).

The joint learning sessions for the teacher trainers' group in the elementary school track included aspects of a learning professional community: joint responsibility for the students' learning; a cooperative emphasis in the learning processes; an open and cooperative approach developed over the course of the learning sessions; and deepening mutual trust and support (Bolam et al., 2005; Koster \& Dengerink, 2008).

The sessions devoted to joint reflection by the teacher trainers about the content of the studies encouraged and accelerated the implementation of the process of change. These sessions facilitated a redefinition of the desired outcomes of the various stages of the process of change itself (Sergiovani,1996), as well as reexamination of the activities and implementation during this process (Schon, 1983).

The joint learning sessions promoted a teaching style among the new teacher trainers and reinforced their learning by adding practical tools and strategies for teaching in the heterogeneous class. This group of teacher trainers will form the backbone of the elementary school track over the coming years, and the processes of learning and implementation they experienced over the year may play a significant role in shaping the character and style of training in the elementary school track. This experience may also help shape the future intake and learning of new teacher trainers who join the elementary school track.

In all probability, significant change will only be possible over a longer timeframe (Robinson \& Sebba, 2004). In many cases, limiting the time allocated for complex learning processes impairs their quality (Lyman \& Foyle, 1993; Day, 1999). Accordingly, it is important to develop an ongoing process of joint learning sessions for the entire team of teacher trainers (Day, 1999).

The study's findings may help processes of learning and development for teacher trainers in the elementary school track in particular, and in other education tracks. It can create a theory that should shed light on other attempts that were carried out or examined under different circumstances (Pryor \& Piper, 1994). These findings highlight and underscore the great complexity of these processes; the difficulties and strengths they embody; and the considerable potential their implementation offers for the professional and personal development of the teacher trainers.

\section{Bibliography}


[1] Avissar, G. (2009). Academic success of the student with disabilities in the regular class - is it possible? Issues in Special Education and Integration, 24, 5-22. (in Hebrew).

[2] Ayalon, Y., \& Tzabar Ben Yehoshua, N. (2009). A process of content analysis in accordance with field-based theory. In L. Kessen \& M. Kromer-Nevo (Eds.), Data analysis in qualitative research (pp. 359-382). Beer Sheva: BenGurion University. (in Hebrew).

[3] Bar Ziv, Y. (2007). The teacher trainer in teacher training colleges in Israel: The perception of the position with reference to existential styles. (Doctoral dissertation). University of Alta, Hungary.

[4] Beck, S. (2013). The changing face of teacher training in education colleges in Israel. In S. Shimoni \& A. Avidav-Unger (Eds.), On the continuum of training, specialization, and professional development - policy, theory, and practice (pp. 6094). Tel Aviv: Mofet. (in Hebrew).

[5] Ben Ari, R. \& Ritz, Y. (1994). The heterogeneous class. Even Yehuda: Reches Publishers. (in Hebrew).

[6] Bolam, R., McMahon, A., Stoll, L., Thomas, S., \& Wallace, M. (2005). Creating and sustaining effective professional learning communities. Nottingham: DFES.

[7] Brickner, R., Yosifon, M., Zahavi, Y., \& Hacham, A. (1997). Adapted teaching in a heterogeneous class. Ramat Aviv: Center for Educational Technology. (in Hebrew).

[8] Buber, M. (1963). On the educational act: The hidden dialogue. Jerusalem: Bialik Institute. (in Hebrew).

[9] Butink, J. (2009). What and how student teachers learn during school based teacher education. Teaching and Teacher Education, $25,118-127$.

[10] Chen, D. (1989). Diversity in the population. Tel Aviv: Open University. (in Hebrew).

[11] Cochran-Smith, M., \& Power, C. (2010). New directions for teacher preparation. Educational Leadership, 19, 6-13.

[12] Cohen, S. (2011). Teachers' response to change: Factors influencing the affiliation of teachers to the 'New Horizon' reform in Israel. Jerusalem: Hebrew University. (in Hebrew).

[13] Cohen, L., Manion, L. \& Morrison, K. (2000). Research Methods in Education (5th ed.). London: Routledge.

[14] Cordingley, P., Bell, M., Rundell, B., \& Evans, D. (2003). The impact of collaborative CPD on classroom teaching and learning. London: EPPI-Centre, Social Science Research Unit, Institute of Education.

[15] Crono, L., \& Snow, R.E. (1986). Adapting teaching to individual differences among learners. In M.C. Wittrock (Ed.), Handbook of research on teaching. New York: Macmillan.

[16] Day, C. (1999). Developing teachers: The challenge of lifelong learning. London: Falmer Press.

[17] Day, C. (2003). Designing longitudinal research on variations in teachers' work, lives and effectiveness - an overview. In British Educational Research Association Annual Conference, Edinburgh.

[18] Donaldson, J.G., \& Sanderson, D.R. (1996). Working together in schools. Thousand Oaks, CA: Corwin Press.

[19] Dean, J. (1991). Professional development in school. Philadelphia: Open University Press.

[20] Elliot, J. (1991). Action research for educational change. Philadelphia: Open University Press.

[21] Fielding, M. (1999). Radical collegiality: Affirming teaching as an inclusive professional practice. Australian Educational Research, 26, 1-34.

[22] Hacohen, R., \& Zimran, A. (1999). Action research. Tel Aviv: Mofet Institute. (in Hebrew).

[23] Hargreaves, A., Earl, L., \& Ryan, J. (1996). Schooling for change. London: Falmer Press.

[24] Keinan, E., \& Assaf, M. (2004). The teacher trainer. In Who are you, teacher trainer? (pp. 35-52). Beersheva: Ben Gurion University of the Negev. (in Hebrew).
[25] Koster, B., \& Dengerink, J.J. (2008). Professional standards for teacher educators: How to deal with complexity ownership and function experience from the Netherlands. European Journal of Teacher Education, 31 (2), 135-149.

[26] Lorrigan, G. (2001). Practising professional development: Plans, principles and problems. In T. Ariav (Ed.), The ongoing development of teacher education: Exchange of ideas. (pp. 82-95). Tel Aviv: Mofet.

[27] Lunenberg, M., Korthagen, F., \& Swennen, A. (2007). The teacher educator as a role model. Teaching and Teacher Education, 23, 586-601.

[28] Lyman, L., \& Foyle, H.C. (1993). Cooperative grouping for interactive learning. Washington DC: National Education Association.

[29] Mishler, E. (1986). Research interviewing: context and narrative. Boston: Harvard University Press.

[30] Orland-Barak, N. (2002). The impact of the assessment of practice teaching on beginning teaching: Learning to ask different questions. Teacher Education Quarterly, 99-122.

[31] Parag, R., \& Inbar, L. (1999). The edge of the century. Jerusalem: Achva.

[32] Patthey, G.D., \& Thomas-Spiegel, J. (2013). Action research for instructional improvement: the bad, the ugly and the good. Educational Action Research, 21 (4), 468-484.

[33] Pryor, J., \& Piper, J. (1994, September). Teacher researching teachers: An approach to action research in schools. Paper presented to the Annual Conference of the British Educational Research Association, Oxford, UK.

[34] Robinson, C., \& Sebba, J. (2004). A review of research and evaluation to inform the development of the new postgraduate professional development programme. TTA / University of Sussex.

[35] Schon, A.D. (1983). The reflective practitioner: How professionals think in action. London: Temple Smith.

[36] Schuck, S., Aubusson, P., \& Buchanan, J. (2008). Enhancing teacher education practice through professional learning conversations. European Journal of Teacher Education, 31 (2), 215-227.

[37] Sergiovanni, J.T. (1996), Leadership for the Schoolhouse. San Francisco: Jossey-Bass Publishers.

[38] Thyggvason, M.T. (2009). Why is Finnish teacher education successful? Some goals Finnish teachers educators have for their teaching. European Journal of Teacher Education, 32 (4), 369382.

[39] Tomer, E. (2000). Teacher trainers: Affinities between their perception of the role and teaching style and the circumstances of training. (Doctoral dissertation). Beersheva: Ben Gurion University of the Negev. (in Hebrew).

[40] Van Diggelen, M., Den Broke, P., \& Beijaard, D. (2013). Teachers' use of self- assessment procedure: the role of criteria, standards, feedback and reflection. Teacher and Teaching: Theory and Practice, 19 (4), 115-134.

[41] Wallace, M.J. (2002). Action research for language teachers. Cambridge: Cambridge University Press.

[42] Zilberstein, M. (2002). The role of case literature in teacher training programs. In M. Zilberstein \& P. Katz (Eds.), Training events and teaching events - the pedagogy of case literature in teacher training, (pp. 6-35). Tel Aviv: Mofet Institute. (in Hebrew).

[43] Zilberstorm, S. (2013). The entry stage to the teaching profession in light of theory and practice. In S. Shimoni and A. AvidavUnger (Eds.), On the continuum of training, specialization, and professional development - policy, theory, and practice, (pp. 101132). Tel Aviv: Mofet. (in Hebrew). 